\title{
Empathy in Negative and Positive Interpersonal Interactions. What is the Relationship Between Central (EEG, fNIRS) and Peripheral (Autonomic) Neurophysiological Responses?
}

\author{
Michela Balconi ${ }^{1,2}$ and Maria Elide Vanutelli ${ }^{1,2}$ \\ ${ }^{1}$ Research Unit in Affective and Social Neuroscience, Catholic University of the Sacred Heart, Milan, Italy \\ ${ }^{2}$ Department of Psychology, Catholic University of the Sacred Heart, Milan, Italy
}

ABSTRACT

Emotional empathy is crucial to understand how we respond to interpersonal positive or negative situations. In the present research, we aim at identifying the neural networks and the autonomic responsiveness underlying the human ability to perceive and empathize with others' emotions when positive (cooperative) or negative (uncooperative) interactions are observed. A multimethodological approach was adopted to elucidate the reciprocal interplay of autonomic (peripheral) and central (cortical) activities in empathic behavior. Electroencephalography (EEG, frequency band analysis) and hemodynamic (functional Near-Infrared Spectroscopy, fNIRS) activity were all recorded simultaneously with systemic skin conductance response (SCR) and heart rate (HR) measurements as potential biological markers of emotional empathy. Subjects were required to empathize in interpersonal interactions. As shown by fNIRS/EEG measures, negative situations elicited increased brain responses within the right prefrontal cortex (PFC), whereas positive situations elicited greater responses within the left PFC. Therefore, a relevant lateralization effect was induced by the specific valence (mainly for negative conditions) of the emotional interactions. Also, SCR was modulated by positive/negative conditions. Finally, EEG activity (mainly low-frequency theta and delta bands) intrinsically correlated with the cortical hemodynamic responsiveness, and they both predicted autonomic activity. The integrated central and autonomic measures better elucidated the significance of empathic behavior in interpersonal interactions.

\section{interpersonal empathy, positive/negative interac- tions, fNIRS, brain oscilla- tions; autonomic activity \\ KEYWORDS}

INTRODUCTION

The abilities to monitor and regulate emotional processes are parts of a functional model of empathic behavior (Chauhan, Mathias, \& Critchley, 2008) which includes processes of emotional resonance. These are constituted by an affective response to another person, which often entails knowing what another person is feeling; sharing that person's emotional state; and, in some cases, having the intention to respond compassionately to another person's distress (Decety \& Jackson, 2006; Hooker, Verosky, Germine, Knight, \& D’Esposito, 2008; Ickes, 1997; Preston \& de Waal, 2002). Specifically, the emotional behavior, in ad- dition to the cognitive ability to share representations, constitute the basic components of empathy (Decety \& Svetlova, 2012).

However, limited previous studies explored empathy by using stimuli consisting of real interpersonal situations. In fact, previous research

Corresponding author: Michela Balconi, Department of Psychology, Catholic University of the Sacred Heart, Largo Gemelli, 1, 20123, Milan, Italy. Phone: +39-2-72342586; fax: +30-2-72342280. E-mail: michela.balconi@unicatt.it E-mail: mariaelide.vanutelli@unicatt.it 
mainly focalized on the emotional response to generic emotional cues and it did not include a specific empathic task (Balconi \& Bortolotti, 2014; Balconi, Grippa, \& Vanutelli, 2015a; Herrmann et al., 2008), or it explored facial expressions of emotions (Balconi \& Canavesio, 2013; Herrmann et al., 2008) or empathy in specific domains (such as empathic responses to pain conditions, Avenanti, Sirigu, \& Aglioti, 2010; Rêgo et al., 2015; Wang, Wang, Hu, \& Li, 2014). In addition, exiguous research monitored analytically the effect induced by different types of empathic situations - that is, the positive versus negative valence of the situations in which the subjects were required to empathize (Balconi \& Bortolotti, 2014; Herrmann et al., 2008; Silani \& Singer, 2015). In one case, the valence effect was explored in an empathic context, although no specific effect was found in relation to both valence of the situation (positive or negative) and lateralization of brain activity (left or right) considered together. In other cases (see, e.g., Tullett, Harmon-Jones, \& Inzlicht, 2012), significant right lateralized prefrontal patterns have been found in the case of empathy in negative circumstances. Here, the authors suggested the mediation of feelings of sadness in the development of the empathic mechanisms towards the suffering of other, together with the elicitation of prefrontal asymmetry. Nonetheless, results have often been proven to be inconsistent (see, e.g., Morelli \& Lieberman, 2013).

In the current study, we explored in an empathic context, both the valence of the situation (positive or negative) and the lateralization of brain activity (left or right). From a neurophysiological point of view, it has been established that empathic responses influence both cortical activity (Brüne et al., 2012; Decety \& Jackson, 2006; Rameson \& Lieberman, 2009; Thirioux, Mercier, Blanke, \& Berthoz, 2014) and autonomic physiological responsiveness (Balconi \& Bortolotti, 2012b; Eisenberg et al., 1989; Prguda \& Neumann, 2014). Indeed, as suggested by empathy models, the indubitable vantage of acquiring both autonomic and central activities is the possibility to better elucidate the reciprocal interplay of these two domains (Decety \& Svetlova, 2012; Preston \& de Waal, 2002). The multidimensionality of the construct of empathy makes it less compatible with single measures. However, so far central and peripheral measures were scarcely related to each other in empathy research (Balconi \& Bortolotti, 2012b). The current study addresses this research gap.

Concerning cortical activity correlates of empathy, previous neuroimaging studies on the emotional behavior in relation to empathy have revealed a range of areas activated in response to empathic interactions, specifically, during general emotional processing, the medial prefrontal cortex (MPFC, Seitz, Nickel, \& Azari, 2006; ShamayTsoory \& Aharon-Peretz, 2007) and the dorsolateral prefrontal cortex (DLPFC, Balconi \& Bortolotti, 2012a; Balconi, Bortolotti, \& Gonzaga, 2011; Brüne et al., 2012; Damasio, Everitt, \& Bishop, 1996; Davidson, 2002; Ochsner \& Gross, 2005; Rameson, Morelli, \& Lieberman, 2012). Moreover, electroencephalography (EEG) and lesion studies indicated that the prefrontal cortex (PFC) plays a prominent role in mediating empathy-related behaviors. Specifically, many studies reported a significant prefrontal involvement for the disruption of empathic behavior in the case of psychopathy (for a review see Pera-Guardiola et al., 2016). For example, as has been found by Howard and McCullagh (2007) in conditions involving both a categorization and a vigilance task with affective stimuli, psychopaths showed significantly smaller positive Slow Wave (pSW) amplitudes than healthy controls during the categorization task, where they were required to discriminate between living and nonliving stimuli, thus reflecting insensitivity to an affective mismatch between neutral backgrounds and positive pictures. Also, psychopaths showed a larger prefrontal negative event-related potential (ERP, N350), the amplitude of which positively correlated with the behavioral markers of psychopathy. Similarly, Kiehl, Hare, McDonald, and Brink (1999), by conducting a task comparing semantic and affective verbal information, reported greater centrofrontal negative-going wave amplitudes in psychopaths than controls.

However, neither classical functional magnetic resonance imaging (fMRI) nor EEG seem to have completely uncovered in depth the physiological correlate of the emotional empathic experience, as both of these methods have their shortcomings: a low temporal resolution of fMRI and a low spatial resolution of activity below the cortical surface plus an insensitivity to the hemodynamic response of the EEG. Therefore, we applied optical imaging (i.e., near-infrared spectroscopy, NIRS) as a complementary method in the study of emotions and empathy. NIRS is particularly well-suited for evaluating PFC activity, which is among the regions involved in emotional processing (i.e., the frontopolar cortex and the DLPFC, Doi, Nishitani, \& Shinohara, 2013). Due to its high temporal resolution, a spatial resolution exceeding that of the EEG, and its sensitivity for hemodynamic changes, NIRS seems well suited to study the temporally evolving representation and integration among complex, extended neural networks, of the empathic response. The temporal resolution of NIRS is high enough for measuring event-related hemodynamic responses (Elwell et al., 1993), and combined EEG/NIRS measurements allow for the complementary examination of neural as well as hemodynamic aspects of brain activation (Balconi et al., 2015a; Biallas, Trajkovic, Haensse, Marcar, \& Wolf, 2012).

Specifically, recent studies with functional NIRS (fNIRS) have identified the PFC as a key region in the experience and regulation of emotional responses (Brink et al., 2011; Nomura, Ogawa, \& Nomura, 2010; Ogawa \& Nomura, 2012). Based on this research, also a significant lateralization effect was found, related to the positive versus negative valence of the activating emotional context. Specifically, left PFC areas were more activated in response to positive or approach emotions, whereas right $\mathrm{PFC}$ areas were more activated in response to negative or withdrawal emotions (Balconi et al., 2015a; Balconi, Grippa, \& Vanutelli, 2015b; Tullett et al., 2012).

Concerning EEG, frequency band analysis contributed to elucidating the role of specific cortical areas, mainly with respect to the lateralization effect in emotional empathy processing, too. In fact, brain oscillations may furnish clear brain correlates of specific empathic contexts in terms of their valence (positive or negative) and in relation to cortical lateralization. However, the specific role of brain oscillations in affective and empathic behavior is partially unknown (Balconi \& Lucchiari, 2006, 2008; Başar, 1999; Vanutelli \& Balconi, 2015). Only 
few studies used brain oscillations to study empathy (Gutsell \& Inzlicht, 2012; Moore, Gorodnitsky, \& Pineda, 2012; Mu, Fan, Mao, \& Han, 2008; Tullett et al., 2012). What is known from related investigations outside empathy research proper is that, regarding the alpha frequency band, lower-1 alpha desynchronizes in response to a warning stimulus (Klimesch, Doppelmayr, Russegger, Pachinger, \& Schwaiger, 1998). Overall, changes in alpha power and lateralization effects related to these changes suggested that a right frontal unbalance is associated with negative emotions while relatively stronger left frontal activation is associated with positive emotions (Bekkedal, Rossi, \& Panksepp, 2011). An anterior asymmetry was found in alpha activity that was explained as a correlate of changes in the affective state (Balconi, Brambilla, \& Falbo, 2009a, 2009b; Davidson, 1998; Dimberg \& Petterson, 2000). In addition, some studies showed that theta band power responds to prolonged visual emotional stimulation (Knyazev, 2007; Krause, Enticott, Zangen, \& Fitzgerald, 2012). Therefore, the modulation of this frequency band may significantly contribute to the explanation of arousal effects on emotional cue comprehension (Bekkedal et al., 2011). In contrast, exiguous data concern the modulation of delta and beta band when considering the emotional significance of a stimulus (Karakaş, Erzengin, \& Başar, 2000). In some cases, it was shown that delta could be a marker of novelty of the emotional cues and that it can respond to the exigency of stimulus updating in memory (Fernández et al., 1998).

Finally, as markers of spontaneous and automatic empathic behavior, autonomic measures are very important for understanding the relationship between empathy and autonomic measures. It has been observed that different degrees of empathic experience may affect autonomic psychophysiological responses (Balconi, Falbo, \& Conte, 2012; Prguda \& Neumann, 2014). In those cases, participants imagined (a) a personal experience of fear or anger from their own past, (b) an equivalent experience from another person as if it were happening to them, or (c) a non-emotional experience from their own past (Ruby \& Decety, 2004). Autonomic differences were found between these conditions. Nevertheless, in this approach, only imagined (and not real) empathic situations were proposed and this fact may have introduced important variations in the subjective responses.

Systemic blood pressure (BP), heart rate (HR), and skin conductance response (SCR) were considered as potential biological markers of emotions in empathic behavior, and recorded simultaneously with EEG and NIRS (Tupak et al., 2014). Among the other dependent variables, SCR provides a useful measure of limbic function (Furmark, Fischer, Wik, Larsson, \& Fredrikson, 1997; Lang, Davis, \& Öhman, 2000). It is also a significant measure of arousal modulations, as has been demonstrated previously (Balconi et al., 2009a; Balconi \& Pozzoli, 2008; Bradley \& Lang, 2000).

Also several NIRS studies underlined the association between PFC activation and autonomic responses to emotional stimulation (see, e.g., Tanida, Katsuyama, \& Sakatani, 2007). Likewise, during viewing of trauma-related video clips, increased hemodynamic activity (oxy-hemoglobin, $\mathrm{O} 2 \mathrm{Hb}$ ) has been found to be positively correlated with heart rate change (Matsuo et al., 2003). Furthermore, Moghimi, Kushki, Guerguerian, and Chau (2012) have linked the steepness of the
$\mathrm{O} 2 \mathrm{Hb}$ peak to subjectively reported arousal levels, which is a widely accepted indicator of autonomic system activation (Matsuo et al., 2003; Roos, Robertson, Lochner, Vythilingum, \& Stein, 2011). Moreover, a significant correlation between ventromedial prefrontal cortex (vmPFC) activation and SCR was found, based on stimulus content (its threatening value, Tupak et al., 2014).

These previous studies supported the view that the prefrontal areas regulate autonomic reactions or somatic markers associated with emotional conditions. However, such research lacked a detailed and integrated analysis of all three levels (hemodynamic, electrophysiological, and autonomic) involved in emotional processing during empathic interactions. Only one previous study directly compared hemodynamic, EEG, and autonomic measures, but, firstly, it focused on generic emotional cues and, secondly, it was not on empathy (Balconi et al., 2015a). In contrast, the present research first of all clearly focused on empathic behavior by asking participants "to put themselves in the shoes of another person and try to feel what this person is feeling" (as reported in the procedural instructions). Secondly, the participants were required to observe situations where subjects performed specific interactions and not simply a generic emotional display (such as emotional pictures or faces). Therefore, in comparison with previous studies, a highly empathic task was included.

In conclusion, in light of current knowledge on empathy, we propose an integration of cortical (EEG and fNIRS) measures with autonomic psychophysiological measures, as they have been shown to indicate the presence of emotional tuning between subjects. In the present study, EEG (frequency band analysis), systemic SCR and HR were all recorded simultaneously with fNIRS measurements as potential biological markers of emotional responses to empathic situations during a natural and interpersonal situation in which positive versus negative contexts were represented.

A consistent prefrontal activation was expected, as indicated by a hemodynamic modulation and brain oscillations. Both fNIRS and brain oscillations were supposed to elicit a significant PFC response to emotional interpersonal conditions. Specifically, as a correlate of an empathic response, we firstly expected a higher synchronous brain activity in low-frequency bands (delta and theta) and, in contrast, a desynchronization of the alpha band. Moreover, based on valence and lateralization effects of emotions (Balconi \& Mazza, 2010; Russell, 2003), a significant and consistent higher prefrontal left activation was expected for positive emotional interactions, whereas a consistent higher prefrontal right activation was expected in response to negative interactions. Secondly, we expected that electrodermal activity (SCR) and HR could be significant measures of implicit reactivity to emotional cues; they should consistently vary with emotional valence, with larger responses (increased SCR and HR) elicited in either negative or positive or both emotional conditions compared to neutral situations (Balconi et al., 2009a; Bradley \& Lang, 2000; Lang, Greenwald, Bradley, \& Hamm, 1993).

Thirdly, we expected a high coherence between the three measures (fNIRS, EEG, and autonomic variations). Significant correlations were hypothesized based on situational and interpersonal significance 
(valence) of the empathic context. Indeed, we expected a relevant modulation within the left and right PFC for hemodynamic activity in concomitance with electrophysiological and autonomic response.

\section{MATERIALS AND METHODS}

\section{Subjects}

Twenty-two subjects, 12 females and 10 males $\left(M_{\text {age }}=24.5\right.$ years; $S D$ $=3.53$; age range from 20 to 33 years) participated in the experiment. All subjects were right-handed (Edinburgh Handedness Inventory, Oldfield, 1971), with normal or corrected-to-normal visual acuity. Exclusion criteria were neurological or psychiatric pathologies of the subjects or their close family members. Specifically, they did not show deficits related to depression (Beck Depression Inventory II, BDI, Beck, Steer, \& Brown, 1996) and to anxiety (State-Trait Anxiety Inventory, STAI, Spielberger, Gorsuch, Lushene, Vagg, \& Jacobs, 1970): Exclusion criterion of the BDI Inventory was 19 points or lower $(M=8.95$; $S D=$ 0.46; score range from 2 to 12 points); for the STAI 39 points or lower ( $M$ $=28.45 ; S D=1.03$; score range from 27 to 45 points). No payment was provided for participation. Participants gave informed written consent and the research was approved by the Ethical Committee institution where the work was carried out. The experiment was conducted in accordance with the Declaration of Helsinki, and all the procedures were carried out with adequate understanding by the subjects. The Research Consent Form was submitted before participation in the study.

\section{Stimuli}

Subjects were required to view affective images depicting real interpersonal situations which represented two people who interacted in a common and familiar situation (e.g., at home, in a workplace, or on a journey). Colored images (16 cm in width and $10 \mathrm{~cm}$ in height) representing positive, negative, and neutral interactions were selected. Twenty-four pictures were used for each type of interaction. Positive interactions represented positive and emotionally comfortable situations (such as a handshake between two people); negative interactions represented negative and emotionally uncomfortable situations (such as a quarrel between two people); neutral pictures represented interactions without a specific emotional valence (such as two people sitting on a couch, see Figure 1). All images were similar in their perceptual features (i.e., their luminance, complexity, i.e., number of details in the

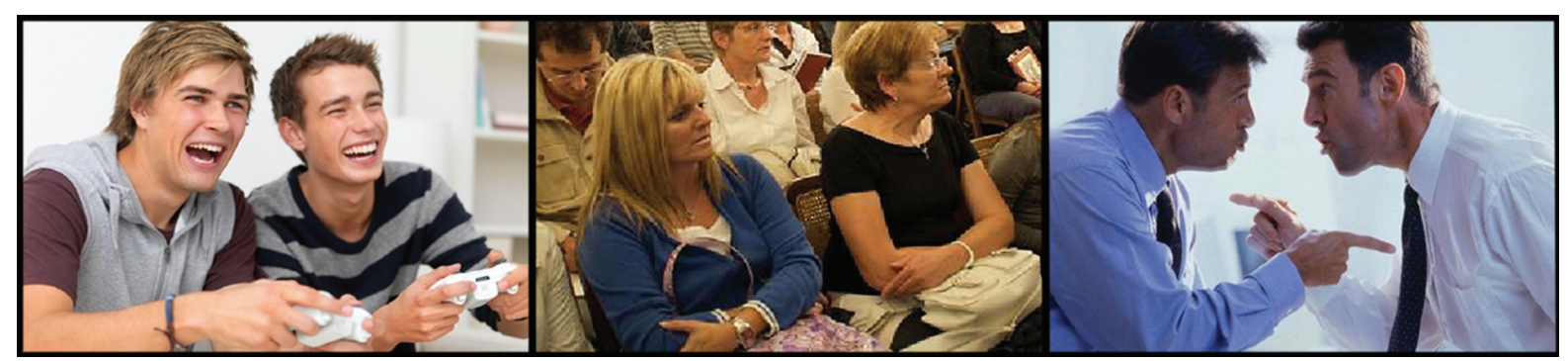

FIGURE 1.

Some examples of positive, neutral, and negative interactions. scene, and characters' genders: half of the actors were male and half were female).

In order to validate the image dataset, a pre-experimental procedure was adopted. Each depicted scene was evaluated by four judges on valence and arousal dimensions, using the Self-Assessment Manikin Scale (SAM) with a five-point Likert scale (Bradley \& Lang, 1994, 2007). Separately for each condition (positive, negative, and neutral), ratings were averaged across all images presented. As shown by statistical analysis (two distinct repeated-measures analyses of variance [ANOVAs] applied to valence and arousal), images firstly differed in terms of valence (positive: $M=4.56, S D=0.34$; negative: $M=1.33$, $S D=0.26$; neutral: $M=2.75, S D=0.37$ - -positive interactions were more positively rated than the other two categories, negative interactions were more negatively rated than the other two categories, neutral images were rated to be of intermediate valence between the other two categories (for all significant contrast comparisons, $p \leq .01$ ). Secondly, with respect to arousal, the positive and negative interactions (positive: $M=4.23, S D=0.24$; negative: $M=4.72, S D=0.25$; neutral: $M=$ $1.77, S D=0.31$ ) were rated as more arousing than the neutral interactions (for all significant contrast comparisons, $p \leq .01$ ). In contrast, no significant differences were revealed between positive and negative interactions $(p=.32)$.

\section{Procedure}

Subjects were seated in a dimly lit room, facing an LCD computer monitor that was placed at about $50 \mathrm{~cm}$ from the subject. The stimuli were presented using E-Prime 2.0 software (Psychology Software Tools, Inc) running on a laptop PC with a 15 in. screen (Acer TravelMate 250P). Images were presented in a random order in the center of the screen for $6 \mathrm{~s}$, with an inter-stimulus interval of $8 \mathrm{~s}$ (see Figure 2).

Participants were required to view each stimulus during fNIRS/ EEG measures recording, and they were asked to attend to the interpersonal situations during the entire time of exposition, focusing on the emotional conditions which characterized the represented human actors. Moreover, they were required to empathize with the two persons interacting with each other ("Try to put yourself into the shoes of the persons and to experience their feelings in this situation"). In order to facilitate empathizing with the depicted actors, the two actors were of about the same age as the experimental subjects.

Before scene presentations, a 2 min resting period was registered at the beginning of the experiment. Next, a familiarization phase followed, in which subjects saw and evaluated a set of images (one of each emo- 


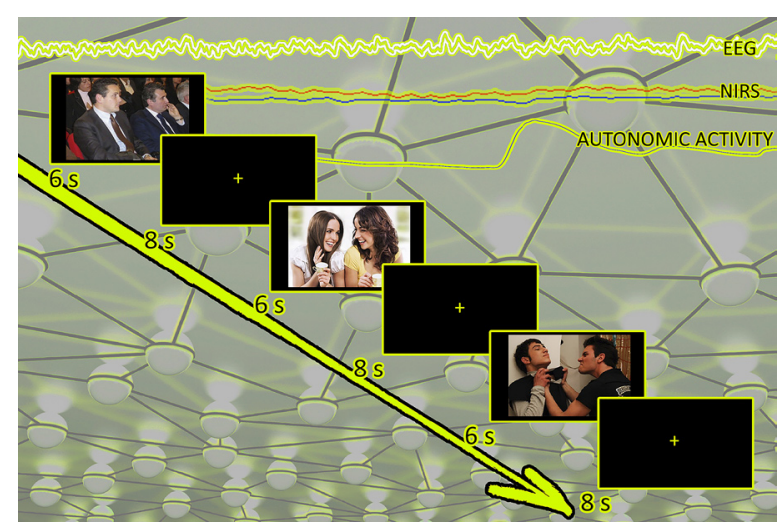

FIGURE 2.

Experimental setting with $\mathrm{fNIRS}$, EEG, and autonomic measures.

tional category), different from the images used in the experimental phase. After the experimental phase, subjects were required to rate the pictures with the SAM on valence and arousal dimensions. As shown by statistical analysis (two repeated-measures ANOVAs for the valence and arousal measures), images differed in terms of valence (with more positive evaluations of positive than negative and neutral interactions, with more negative evaluations of negative than positive and neutral interactions, and with intermediate evaluations of neutral compared to positive and neutral interactions) and arousal (with significant differences between positive and neutral interactions, and between negative and neutral interactions, showing a higher arousal rating for positive and negative interactions). For all paired comparisons significance was assumed for an alpha level of .01 or lower.

A specific questionnaire was used in order to assess the subjects' self-rating on key aspects of the subjective evaluation of the empathic task. The questionnaire was used in a de-briefing post-experimental section (a five-point Likert scale for each item, from low to high). The aspects examined included the degree of experienced empathy ("How much did you put yourself into the shoes of the actors and felt what they felt in the depicted situation?"), personal emotional involvement ("How much did you feel emotionally involved in the situation?"), semantic attribution of the situation (positive, negative, and neutral, "How did you classify the interpersonal situation?"), and emotional significance (high or low, "Did you perceive an emotional significance of the situation?"). All subjects experienced a high sense of empathy ( $M=4.11, S D=0.26)$, were emotionally engaged in the task $(M=4.23$, $S D=0.34$ ), and were able to attribute a coherent emotional value to the pictures (for coherent semantic attribution of valence: $M=4.09, S D=$ 0.32 ; for emotional significance: $M=4.88, S D=0.45$ ).

\section{EEG: Frequency Band Analysis}

A 16-channel portable EEG-System (V-AMP, Brain Products) was used for data acquisition. An NIRS-EEG compatible ElectroCap with $\mathrm{Ag} / \mathrm{AgCl}$ electrodes was used to record EEG from active scalp sites referred to earlobe (10/5 system of electrode placement). EEG activity was recorded from the following positions: AFF3, AFF4, Fz, AFp1, AFp2, C3, C4, Cz, P3, P4, Pz, T7, T8, O1, and O2 (for examples, see
Figure 3). The cap was fixed with a chin strap to prevent shifting during the task. Additionally, one EOG electrode was placed on the lower side of the left eye.

Data preprocessing has been conducted with BrainVision Analyzer 2 (Brainproducts). The data were recorded using a sampling rate of $500 \mathrm{~Hz}$, with a notch filter of $50 \mathrm{~Hz}$. The impedance of recording electrodes was monitored for each subject prior to data collection, and it was always kept below $5 \mathrm{k} \Omega$ (rejected epochs $4 \%$ ). Blinks were also visually monitored. Ocular artefacts (eye movements and blinks) were corrected using an eye-movement correction algorithm that employs a regression analysis in combination with artefact averaging. After EOG correction and visual inspection, only artefact-free trials (not less than 22) were considered. To obtain a signal proportional to the power of the EEG frequency band, the filtered signal samples were squared and successively log-transformed (Pfurtscheller, 1992). Successively, the data were epoched, using a time window of $1 \mathrm{~s}$ and an average absolute power value was calculated for each electrode and condition. Artefact-free data have been used to compute power spectra for relevant EEG frequency bands by the Fast Fourier transform method (with a Hamming window of a length of $10 \%$ ) that was used to obtain estimates of spectral power $\left(\mu \mathrm{V}^{2}\right)$ in $1 \mathrm{~Hz}$ wide frequency bins for each electrode site. Spectral power values were averaged across all epochs and were then transformed to power density values for different frequency bands. An average of the pre-experimental absolute power (2 $\mathrm{min}$ ) was used to determine the individual power without stimulation. From this reference power value, individual power changes during stimulus viewing were determined as the relative stimulus-related decreases or increases. Digital EEG data (from all 15 active channels)

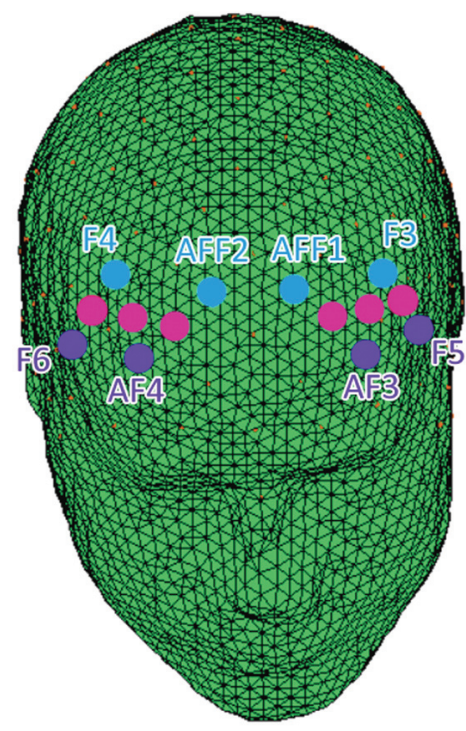

FIGURE 3.

Locations of the prefrontal measurement channels of EEG and fNIRS. For fNIRS, emitter-detector distance was 30 $\mathrm{mm}$ for contiguous optodes and near-infrared light of two wavelengths (760 and $850 \mathrm{~nm}$ ) were used. NIRS optodes were attached to the subject's head using a NIRS-EEG compatible cup, with respect to the international 10/5 system. 
were band-pass filtered in the following frequency bands: delta (0-3), theta (4-7), alpha (8-12), and beta (13-20). During data reduction, a bandpass filter was applied in the $0.01-50 \mathrm{~Hz}$ frequency band.

\section{fNIRS}

fNIRS measurements were conducted with the NIRScout System (NIRx Medical Technologies, LLC) using a six-channel array of optodes (four light sources/emitters and four detectors) covering the prefrontal area. Emitters were placed at AF3-AF4 and F5-F6 while detectors were placed at AFF1-AFF2 and F3-F4 (see Figure 3). Emitter-detector distance was $30 \mathrm{~mm}$ for contiguous optodes and a near-infrared light of two wavelengths (760 and $850 \mathrm{~nm}$ ) was used. NIRS optodes were attached to the subject's head using a NIRS-EEG compatible cup, with respect to the international 10/5 system.

With NIRStar Acquisition Software (NIRx Medical Technologies LLC), changes in the concentration of $\mathrm{O} 2 \mathrm{Hb}$ and deoxygenated hemoglobin $(\mathrm{HHb})$ were recorded from a 2 min starting baseline. Signals obtained from the six NIRS channels were measured with a sampling rate of $6.25 \mathrm{~Hz}$ and analyzed and transformed according to their wavelength and location, resulting in values for the changes in the concentration of $\mathrm{O} 2 \mathrm{Hb}$ and $\mathrm{HHb}$ for each channel. Haemoglobin quantity is scaled in $\mathrm{mM}^{\star} \mathrm{mm}$, implying that all concentration changes depended on the path length of the NIR light in the brain.

With Nirslab Software (v2014.05; NIRx Medical Technologies $\mathrm{LLC}$ ) the raw data of $\mathrm{O} 2 \mathrm{Hb}$ and $\mathrm{HHb}$ from individual channels were digitally band-pass filtered at $0.01-0.3 \mathrm{~Hz}$. Successively, the mean concentration of each channel within a subject was calculated by averaging data across the trials for $6 \mathrm{~s}$ from trial onset. Based on the mean concentrations in the time series, we calculated the effect size in every condition for each channel within a subject. The effect sizes (Cohen's d) were calculated as the differences of the means of the baseline and trial divided by the $S D$ of the baseline, $d=\left(M_{1}-M_{2}\right) / S D_{1}$. Accordingly, $M_{1}$ and $M_{2}$ are the mean concentration values during the baseline and trial, and $S D_{1}$ the $S D$ of the baseline. The mean concentration value of the $2 \mathrm{~s}$ immediately before the trial was used as a baseline. Then, the effect sizes obtained from the six channels were averaged in order to increase the signal-to-noise ratio. Although the raw data of NIRS were originally relative values and could not be averaged directly across subjects or channels, normalized data, such as the effect sizes, could be averaged regardless of the units of measurement (Matsuda \& Hiraki, 2006; Schroeter, Zysset, Kruggel, \& Von Cramon, 2003; Shimada \& Hiraki, 2006). In fact, the effect size is not affected by differential pathlength factor (DPF, Schroeter et al., 2003). Instead of a block design, a continuous trial design was used in the present research.

\section{Autonomic Measures}

Biopac MP 150 system (Biopac Systems Inc) was used to record the autonomic activity. Electrocardiography (ECG) was recorded continuously in lead 1 from two electrodes attached to the lower wrist, with the positive pole on the left arm and the negative pole on the right arm. One more reference electrode was placed over the left ankle. The ECG signal was sampled at $1,000 \mathrm{~Hz}$ with the Biopac Acknowledge 3.7.1 software (Biopac Systems Inc) according to the manufacturer guidelines. ECG was converted to HR in number of beats per minute. The signal was low-pass filtered at $35 \mathrm{~Hz}$ and highpass filtered at $0.05 \mathrm{~Hz}$ for motor and ocular artefacts. For SCR, before attaching the electrodes, the skin was cleaned with alcohol and slightly abraded. The electrodes for SCR were attached to the distal phalanges of the first and second finger of the left hand. SCL was recorded using two $\mathrm{Ag} / \mathrm{AgCl}$ electrodes and an isotonic gel. The signal was low-pass filtered at $10 \mathrm{~Hz}$ for motor, ocular, and biological artefacts. Ocular artefacts were then checked with a visual inspection to eventually eliminate specific elements. Trials with artefacts $(2 \%)$ were excluded from the analysis. SCR elicited by each stimulus was registered continuously with a constant voltage. It was defined as the largest increase in conductance during emotional image presentation, with a cut-off of at least $0.3 \mu \mathrm{S}$ in amplitude with respect to baseline (pre-stimulus) mean values. Baseline values were scored during the 2 min prior to task onset.

\section{RESULTS}

The following set of analyses was performed on the data with SPSS software for Windows (version 18): A first set of repeated-measures ANOVAs was applied to each frequency band, a second set of analyses was applied to hemodynamic $d$ values, and a third set of ANOVAs was applied to autonomic (HR, SCR) measures. Finally, stepwise multiple regression and correlational analyses (Pearson correlations) were applied to compare the three levels (band oscillations, $d$ values, and autonomic measures). Bonferroni correction was inserted for multiple comparisons.

\section{EEG Frequency Band Analysis}

Frequency band data were entered into three-ways repeated-measures ANOVAs, with independent variables of Lateralization (two sides: left channels and right channels), Valence (3), and Localization (three sites: frontal, AFF3/AFF4 and AFp1/AFp2; temporo-central, C3/C4 and T7/ T8; and parietal, P3/P4). Type I errors associated with inhomogeneity of variances were controlled by decreasing the degrees of freedom using Greenhouse-Geiser epsilon. Post hoc comparisons were successively applied to the data (contrast analyses for repeated-measures ANOVA).

As shown by ANOVA, delta was modulated by valence, $F(2,42)=$ $6.16, p=.001, \eta^{2}=.27$, and Lateralization $\times$ Valence, $F(2,42)=7.23$, $p=.001, \eta^{2}=.29$. No other main effect or interaction was statistically significant. Delta increased for negative and positive relative to neutral stimuli. Moreover, it increased for negative more than for positive interactions (for all comparisons, $p \leq .001$ ). In addition, concerning the simple effects for the two-way interaction, significant differences were observed between positive and negative interactions, with increased delta within the right hemisphere for negative, $F(2,42)=5.79, p=.001$, $\eta^{2}=.24$, and within the left hemisphere for positive, $F(2,42)=6.54, p=$ $.001, \eta^{2}=.26$, interactions (see Figure 4).

For theta, the ANOVA revealed a significant main effect of valence, $F(1,13)=6.56, p=.001, \eta^{2}=.33$, and a significant Lateralization $\times$ 


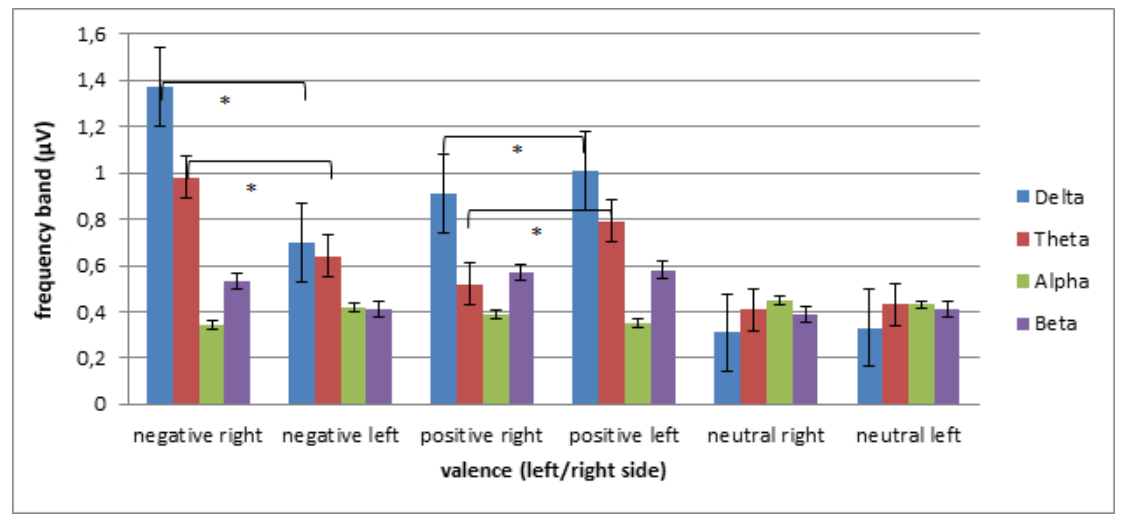

FIGURE 4.

Frequency band power in response to valence and lateralization ( $M$ and $S D$ reported; asterisks mark statistical significance, with $p \leq .05)$.

Valence interaction, $F(2,42)=7.76, p=.001, \eta^{2}=.29$. No other effect or interaction was statistically significant. Theta increased in response to negative relative to positive stimuli. Concerning the two-way interaction, significant differences were observed between positive and negative interactions, with increased delta within the right hemisphere for negative, $F(2,42)=6.09, p=.001, \eta^{2}=.26$, and within the left hemisphere for positive, $F(2,42)=6.43, p=.001, \eta^{2}=.26$, interactions (see Figure 4).

Concerning the alpha band, the valence effect was statistically significant, $F(2,42)=7.15, p=.001, \eta^{2}=.30$. A generally decreased alpha (increased brain activity) was observed for positive and negative interactions. Finally, concerning beta, no significant effects were found (see Figure 4).

\section{fNIRS}

The statistical analysis was applied to $d$-the dependent measure for $\mathrm{O} 2 \mathrm{Hb}$ and $\mathrm{HHb}$-concentrations. The analysis of $\mathrm{HHb}$ did not reveal any significant effects, and for this reason we report results for $\mathrm{O} 2 \mathrm{Hb}$ values only. The lack of any significant effect for $\mathrm{HHb}$ may be due to the increase in $\mathrm{O} 2 \mathrm{Hb}$ that is larger than the decrease in $\mathrm{HHb}$ (Wolf et al., 2002). D was subjected to a repeated-measures ANOVA, with Lateralization (2) and Valence (3) as independent variables. The data were averaged over left (Channel 1: AF3-F3; Channel 2: AF3-AFF1; Channel 3: F5-F3) and right (Channel 4: AF4-F4; Channel 5: AF4AFF2; Channel 6: F6-F4) channels.

As shown by the ANOVA, the effect of valence, $F(2,42)=9.13$, $p$ $<.001, \eta^{2}=.41$, and a Lateralization $\times$ Valence interaction, $F(2,42)=$ $8.13, p<.001, \eta^{2}=.32$, were significant. No other effect or interaction was statistically significant. As shown by paired comparisons, negative and positive stimuli revealed increased $d$ values in comparison to neutral interactions, $F(1,21)=6.70, p<.001, \eta^{2}=.31$, and $F(1,21)=$ $6.62, p<.001, \eta^{2}=.31$, respectively. Moreover, negative interactions showed higher $d$ values for negative than positive interactions, $F(1$, $21)=7.50, p<.001, \eta^{2}=.32$. Regarding the interaction effect, positive stimuli showed an increased brain activity within the left compared to the right hemisphere, $F(1,21)=8.03, p<.001, \eta^{2}=.34$, whereas negative stimuli showed an increased activity within the right compared to the left hemisphere, $F(1,21)=8.88, p<.001, \eta^{2}=.35$ (see Figure 5). In contrast, no significant differences were found for neutral interactions between left and right side, $F(1,21)=1.16, p=.32, \eta^{2}=.16$.

\section{Autonomic Measures}

HR and SCR measures were analyzed with two separate repeatedmeasures ANOVAs, both with Valence (3) as an independent factor. For SCR, the valence main effect was significant, $F(2,41)=8.88, p<$ $.001, \eta^{2}=.32$ : Negative stimuli induced an increased SCR relative to positive and neutral conditions, $F(1,22)=8.11, p<.001, \eta^{2}=.31$, and $F(1,22)=6.90, p<0.001, \eta^{2}=.28$, respectively. Moreover, the positive condition showed increased SCR values compared to neutral, $F(1,22)$ $=7.13, p<.001, \eta^{2}=.30$. For HR, no effect or interaction was sig-

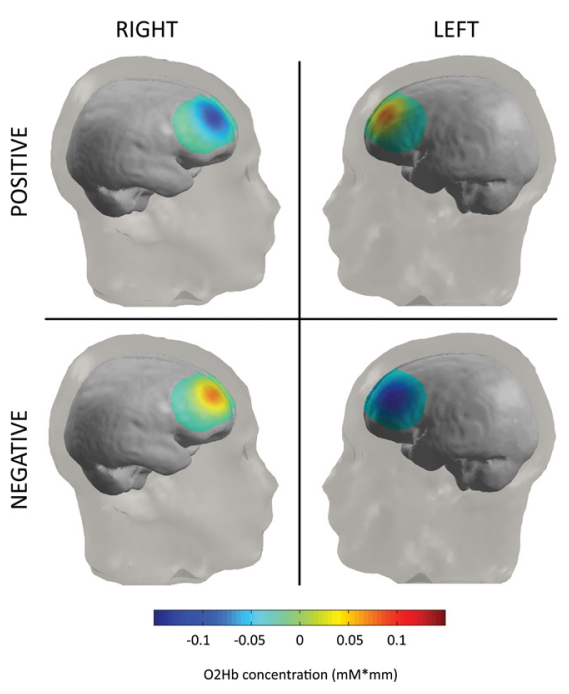

\section{FIGURE 5.}

Hemodynamic states $(\mathrm{O} 2 \mathrm{Hb}$ relative concentrations) as a function of size and valence (obtained with Nirslab Software, Data viewer section, Map tool). In response to negative stimuli, the concentration of $\mathrm{O} 2 \mathrm{Hb}$ was higher for the right than the left side. Moreover, the concentration of $\mathrm{O} 2 \mathrm{Hb}$ was higher in response to negative more than positive stimuli within the right side. 


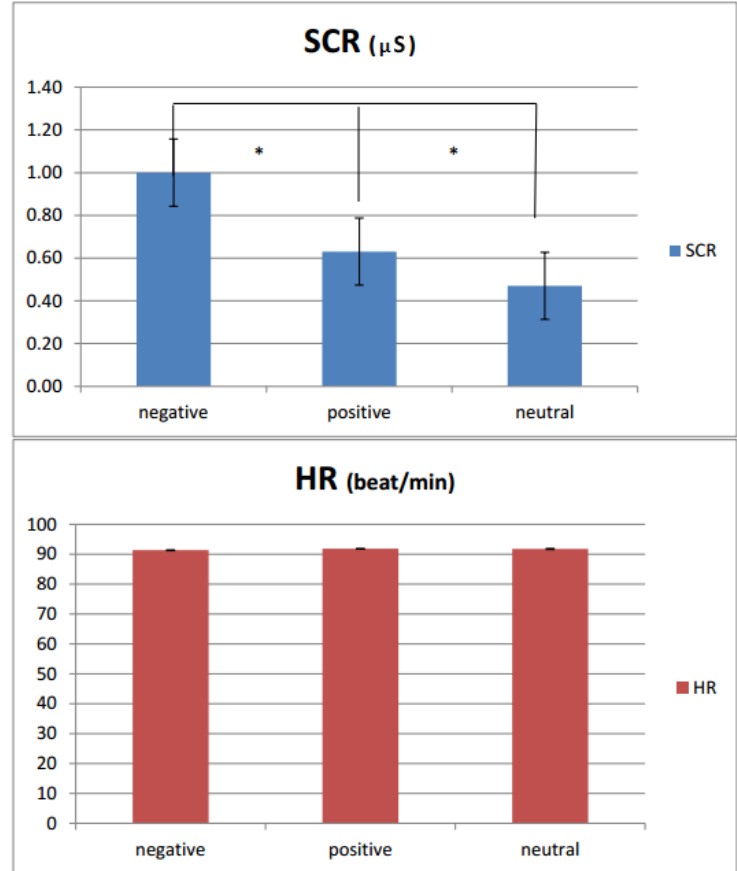

FIGURE 6.

Mean values for SCR (up) and HR (down), with a significant effect shown for SCR based on positive versus negative valence. ( $M$ and $S D$ reported. Asterisks mark statistical significance, with $p \leq .05$.)

nificant (see Figure 6). No other effect or interaction was statistically significant.

\section{Correlational Analyses}

Pearson's correlation analyses (across-subject correlations) were carried out on each frequency band power and $d$ values. Correlations were calculated separately for each valence (positive/negative/neutral interactions) within the left and right prefrontal area. Extensive analyses were also applied to all the EEG and prefrontal fNIRS channels. However, since no significant effect was found in the posterior EEG channels, for the final analysis, we opted to compare the EEG and fNIRS data only for the prefrontal area.

There was a significant positive correlation between $d$ and theta $(r$ $=.491, p<.02$, Variance Inflation factor [VIF] $=.460)$ and between $d$ and delta $(r=.513, p<.01, \mathrm{VIF}=.458)$ bands in response to negative stimuli within the right hemisphere. Moreover, significant positive correlations between $d$ and theta $(r=.561, p<.01$, VIF $=.511)$ and between $d$ and delta $(r=.544, p<.01$, VIF $=.493)$ bands in response to positive stimuli were observed within the left hemisphere. Finally, the alpha band showed a negative correlation with $d(r=-.511, p<.01$, VIF $=.469$ ) within the right hemisphere in response to negative stimuli. That is, cortical activation (alpha decreasing) was revealed within the right hemisphere for negative interactions (see Figure 7). No other correlations were statistically significant.

\section{Regression Analysis}

Two stepwise multiple regression analyses were performed for positive and negative interactions. Predictor variables were Hemodynamic ( $d$
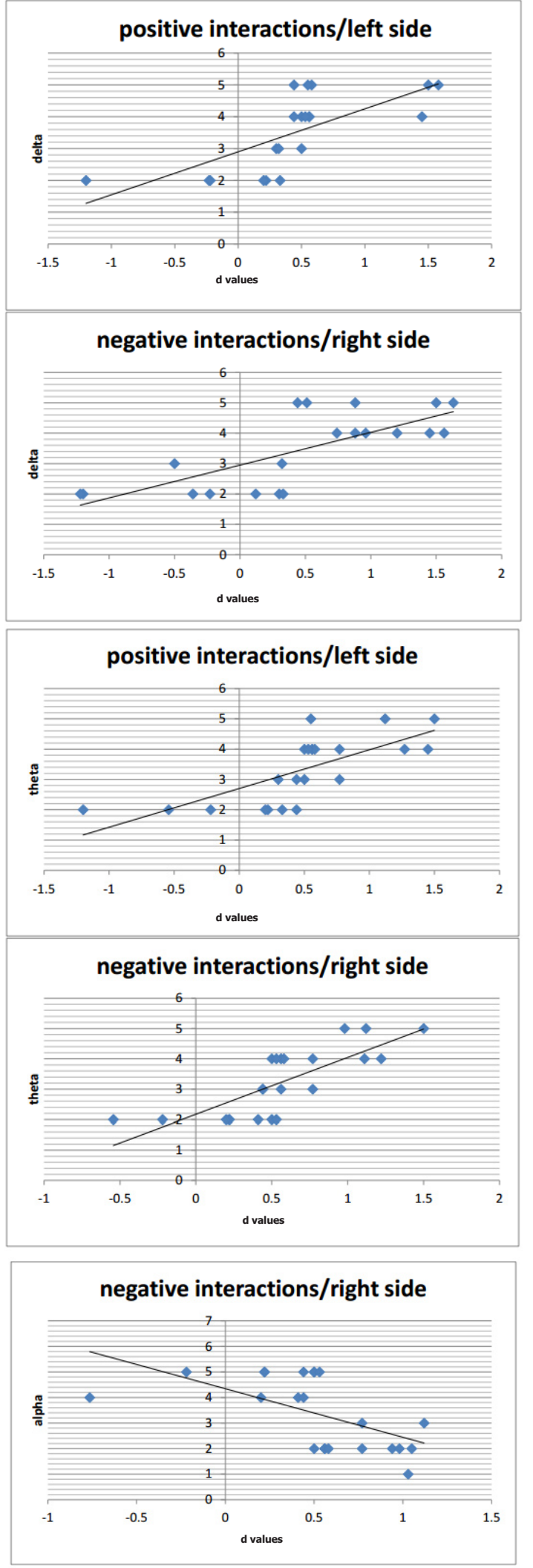

FIGURE 7.

Scatter plots of correlational analyses between hemodynamic and EEG measures as a function of valence and lateralization. Each diamond corresponds to a single participant. 
TABLE 1.

Stepwise Multiple Regressions

a)

\begin{tabular}{|c|c|c|c|c|c|c|c|c|c|c|}
\hline \multirow[b]{2}{*}{ Predictor } & \multicolumn{5}{|c|}{ positive } & \multicolumn{5}{|c|}{ negative } \\
\hline & $d$ values & delta & theta & alpha & beta & $d$ values & delta & theta & alpha & beta \\
\hline Model & 1 & 2 & 3 & 4 & 5 & 1 & 2 & 3 & 4 & 5 \\
\hline \multicolumn{11}{|l|}{ SCR } \\
\hline$R$ & 0.37 & 0.58 & 0.77 & 0.91 & 0.94 & 0.38 & 0.52 & 0.74 & 0.96 & 0.99 \\
\hline$R^{2}$ & 0.13 & 0.33 & 0.59 & 0.82 & 0.85 & 0.14 & 0.26 & 0.48 & 0.85 & 0.89 \\
\hline$\beta$ & 0.34 & 0.27 & 0.27 & -0.31 & 0.25 & 0.20 & 0.23 & 0.32 & -0.30 & 0.20 \\
\hline std error & 0.18 & 0.20 & 0.22 & 0.18 & 0.23 & 0.15 & 0.20 & 0.11 & 0.21 & 0.26 \\
\hline$t$ & $2.12^{\star}$ & $1.84^{\star}$ & $1.63^{\star}$ & $1.75^{\star}$ & 0.98 & $2.35^{\star}$ & $1.87^{\star}$ & $1.99^{\star}$ & $2.01^{\star}$ & 0.75 \\
\hline
\end{tabular}

b)

\begin{tabular}{|c|c|c|c|c|c|c|c|c|c|c|}
\hline \multirow[b]{2}{*}{ Predictor } & \multicolumn{5}{|c|}{ positive } & \multicolumn{5}{|c|}{ negative } \\
\hline & $d$ values & delta & theta & alpha & beta & $d$ values & delta & theta & alpha & beta \\
\hline Model & 1 & 2 & 3 & 4 & 5 & 1 & 2 & 3 & 4 & 5 \\
\hline \multicolumn{11}{|l|}{ HR } \\
\hline$R$ & 0.39 & 0.58 & 0.72 & 0.95 & 0.98 & 0.27 & 0.50 & 0.74 & 0.96 & 0.99 \\
\hline$R^{2}$ & 0.15 & 0.26 & 0.50 & 0.86 & 0.89 & 0.09 & 0.25 & 0.49 & 0.86 & 0.88 \\
\hline$\beta$ & 0.29 & 0.22 & 0.31 & -0.22 & 0.18 & 0.23 & 0.21 & 0.16 & -0.28 & 0.27 \\
\hline std error & 0.25 & 0.20 & 0.26 & 0.20 & 0.21 & 0.20 & 0.25 & 0.24 & 0.20 & 0.17 \\
\hline$t$ & $1.98^{\star}$ & $1.83^{\star}$ & $1.78^{\star}$ & $1.98^{\star}$ & 0.77 & $2.01^{\star}$ & $1.94^{\star}$ & $2.04^{\star}$ & $2.08^{\star}$ & 0.83 \\
\hline
\end{tabular}

Note. (a) $d$, delta, theta, alpha and beta as predictor variables, SCR as predicted variable, and (b) $d$, delta, theta, alpha and beta as predictor variables, HR as predicted variable

values) and EEG measurements, while the predicted variable was the Autonomic Modulation (separately for SCR and HR). In Table 1, we report the cumulative multiple correlations between predictors and predicted variables $(R)$, cumulative proportion of explained variance $\left(R^{2}\right)$, and the regression weights $(\beta)$ for the regression equation at each step of the multivariate analysis. As shown in Table 1, delta, theta, and alpha frequency bands and $d$ values predicted the SCR variations. Increased delta and theta and decreased alpha, as well as increased $d$ were related to increased SCR in case of positive and negative conditions. Similarly, increased delta and theta and decreased alpha band powers, as well increased $d$ were related to increased HR in response to positive and negative interactions.

\section{DISCUSSION}

The present research elucidated some main points to better comprehend the empathic response to interpersonal interactions. Our multilevel analysis, which included three measures (hemodynamic, electrophysiological, and autonomic), allowed us to investigate and support the significant key role of some specific brain areas-that is, the PFC, and some autonomic responses in empathic emotional behavior. Firstly, we found that the PFC was mainly recruited when the subjects empathized with actors in positive or negative interactions.
Secondly, a lateralization effect was also revealed, as shown by both hemodynamic and brain oscillation modulations. Thirdly, the present data supported a significant valence effect, with increased PFC responses in the case of positive and negative interactions. Autonomic activity (SCR) was similarly responsive to the valence of the interactions, even if indistinctively for positive and negative pictures. Finally, a systematic combined modulation was detected for fNIRS and EEG measures, where both have a significant predictive role for autonomic (SCR and HR) activity, since, in the regression, both fNIRS and EEG were predictors of SCR and HR.

The first effect we observed was related to the PFC, which was shown to be responsive to empathic situations where an emotional behavior is involved. $\mathrm{O} 2 \mathrm{Hb}$ increased within the PFC. These results were in line with other results. For example, some recent studies revealed a significant contribution of the right DLPFC in response to positive and negative emotional faces. Along similar lines, right prefrontal stimulation (high frequency repetitive transcranial magnetic stimulation, rTMS) resulted in impaired disengagement from angry faces, with a significant DLPFC effect on attentional processing of emotional information (De Raedt et al., 2010). It was also found that, when activated, the left DLPFC improved processing related to positive emotions and reduced negative emotional processing (Baeken et al., 2010). Neuroimaging studies have provided support for a functionally interactive network 
of cortico-limbic pathways that play a central role in the top-down regulation of emotions. Indeed, a large number of studies suggested that the PFC activates emotion regulation by inhibiting the amygdala (Siegle, Thompson, Carter, Steinhauer, \& Thase, 2007).

Results from previous fMRI studies indicated that the PFC is not only involved in emotion induction but also in emotion regulation. Moreover, by investigating the neural correlates of emotion regulation processes, NIRS studies underlined the role of the PFC. For example, the instruction to decrease the effect of negative stimuli by reinterpreting the displayed situation led to an increased PFC activation and a reduced activation of the amygdala (Banks, Eddy, Angstadt, Nathan, \& Luan Phan, 2007; Eippert et al., 2007; Kalisch et al., 2005; Lévesque et al., 2003; Ochsner, Bunge, Gross, \& Gabrieli, 2002; Ochsner et al., 2004; Phan et al., 2005). Herrmann et al. (2002) used NIRS to compare general emotional cue processing with processing of more specific facial patterns. They found increased medial PFC activity during an emotion induction paradigm which generated emotions by instructing participants to try to feel like a person whose facial expression was displayed. In accordance with these results, the instruction to remember emotional events leads to an increase of activation in the prefrontal brain areas (Ohtani, Matsuo, Kasai, Kato, \& Kato, 2005). Furthermore, patients with post-traumatic stress disorder show increased PFC activation to disorder-related stimuli (Matsuo et al., 2003). In some cases, the social effect of emotional face processing was considered (Nomura et al., 2010). The study of Nomura et al. (2010) employed face stimuli and perspective-taking, and NIRS was used to show the individual differences in empathy that underlie the perspective taking function and the role of the right ventrolateral PFC.

Although all these studies indicated an involvement of the PFC, for the first time in the present research, the empathic emotional response to interactional affective contexts was monitored. In addition, negative versus positive situations were systematically evaluated. Indeed, we revealed that emotional valence affected both hemodynamic activity and brain oscillations, with a more relevant impact for the negative interactions. In addition, this cortical activity was shown to be lateralized within the right hemisphere in response to negative situations and within the left hemisphere in response to positive stimuli. This result clearly supports the view of a lateralization effect in empathic responses to contexts of different valences when an empathic task was administered.

Some specific brain oscillations (mainly delta and theta modulation) confirmed this lateralized activation effect of stimulus valence: Low-frequency oscillations were mainly synchronized within the right and left side in response to negative and positive emotional interactions, respectively. The increased values of delta and theta that we found in response to positive and mainly negative interactions may support the hypothesis that delta plays a main role in regulating the attentional behavior in the case of salient stimuli. In line with this hypothesis, in previous studies, delta band was related to the relevance of the material being processed and to the degree of attention involved in visual stimuli processing (Balconi \& Pozzoli, 2005; Keil et al., 2001). Therefore, in our case, brain responses to negative interactions could suggest that subjects could have perceived them as the most relevant emotional context, since they have a potentially threatening value.

It should be noted that in the present research we did not find a significant and specific effect for higher frequency bands (beta). This is in contrast with previous research (Balconi \& Pozzoli, 2009). These different results may be due to the adoption of different methodological approaches (e.g., task differences) and to different range limits used for the computation of the oscillations.

A similar profile was observed for $\mathrm{O} 2 \mathrm{Hb}$ measure, and the present results thus confirmed the homogeneity of the emotional empathic behavior in response to interpersonal situations by considering the hemodynamic level of analysis. These results were also supported by a consistent cortical lateralization effect for $\mathrm{O} 2 \mathrm{Hb}$, in combination with a specific prefrontal effect. A general left/right positive/negative distinction was observed in the subjects. That is, the subjects showed a distinct cortical lateralized response based on the emotional valence of the interactions: more left localized for positive situations; more right localized for negative situations. Indeed, increased brain activity was found to be based on stimulus valence. It has to be noted though that, compared with some previous research on neuroimaging and NIRS (Herrmann et al., 2008; Hoshi, 2009), we found that valence was relevant for hemispheric lateralization during processing of emotional cues. However, some differences were found based on valence (with increased activation for negative situations), as previously shown by EEG analysis. To account for the differences, we may assume that the most salient contexts to be processed are related to negative interpersonal interactions. Due to this higher degree of salience, higher cortical activation could have been evoked by more negative interactions. In general, it might be concluded that the fNIRS/EEG measures showed a broad sensitivity to the motivational significance of social interactions, varying as a function of the degree of negativity/positivity attributed to the emotional situations. A general right/negative association was observed in the subjects, and it was mainly supported by the right hemisphere-that is, negative, aversive interactions showed a more consistent lateralized brain activation when compared to other emotional situations (i.e., positive situations). Previous research underlined that human emotions are organized by two cortically lateralized systems: the appetitive and defensive motivation systems, presumably evolved from primitive approach and withdrawal tendencies (Balconi \& Bortolotti, 2014; Davidson, 1995; Davidson, Ekman, Saron, Senulis, \& Friesen, 1990; Dickinson \& Dearing, 1978; Lang, Bradley, \& Cuthbert, 1990, 1997, 1998).

In line with this theory, emotional activation fundamentally varies in centrally organized appetitive and aversive motivational systems that have evolved to mediate a wide range of adaptive behaviors that are necessary for an organism to survive (Bradley \& Lang, 2007; Davidson et al., 1990; Lang et al., 1990). Most pleasant affects are held to be associated with the appetitive motivation system; unpleasant affects with defensive motivation (Cacioppo \& Berntson, 1994). Specifically, aversive conditions were considered highly relevant for the survival since they include a threatening value (Fanselow, 1994; Russell, 1980). Also the autonomic behavior was related to empathic behavior, with 
an increased psychophysiological activity (higher SCR) for both positive and negative interactions. This response was attributed to general emotional involvement and to the ability to respond physiologically to the emotions displayed by other people in an interpersonal positive or negative situation. Indeed, as suggested by recent models of empathic behavior, a complex network of central and peripheral circuits supports the phylogenetic developments of a specific empathy-related response to conspecifics' emotional signs. The multiple elements of the empathic response are continuously modified during the social interactions and are contextually embedded (Decety \& Svetlova, 2012). The relation between more central processes (mediated by PFC) and more peripheral processes (mediated by the autonomic system) confirmed the close relation existing between high order mechanisms (evolutionarily recent) and the autonomic responsiveness (evolutionarily ancient). It was also underlined that behaviors specifically supported by arousal evolved earlier than the mechanisms supported by more complex cognitive processes (Decety \& Svetlova, 2012). Moreover, it should be noted that relevant models of empathic behavior have pointed out that the emotional states related to empathy and the underlying neural mechanisms are similar in all mammals (Panksepp, 1998).

The present results are also consistent with previously reported negative, empathy-related responses to unpleasant situations (Brown, Bradley, \& Lang, 2006). Conflictual (negative) and cooperative (positive) situations were shown to be more powerful in eliciting empathic responses, presumably emotionally involving and significant, compared with neutral interpersonal conditions. In particular, the non-cooperative condition was negatively connoted, highly empathy-inducing, and able to produce a clear "negative" consonant autonomic reactivity.

Moreover, positive and negative situations showed a relation between empathic emotional, psychophysiological, and central (both hemodynamic and EEG) measures. Indeed, it should be emphasized that important connections were found in the correlational analysis between hemodynamic and cortical EEG and the regression analyses between these two measures and the responses at the autonomic level. Firstly, the joined EEG-NIRS analysis revealed significant linear associations between the hemodynamic values and brain oscillations. The significant positive relation between NIRS and EEG measures may suggest, on the one hand, a general direct relation between these two measures and PFC activation since they synchronously varied within the prefrontal areas based on a situation's valence. On the other hand, the positive relation may support the connection between these two brain measures in response to empathic situations. More generally, the simultaneous registration of EEG and NIRS was found to be useful for studies on empathic behavior. A general link between electrophysiological effects and the regional hemodynamic changes was suggested based on present and past evidences (Balconi et al., 2015a; Herrmann et al., 2008; Schneider et al., 2014).

To summarize, the significant correlations between EEG and NIRS measures within PFC may suggest that a specific cortical prefrontal area supports empathic responsiveness. Indeed, whereas in band oscillations only a lateralization effect was found, the intrinsic relation between PFC activity observed in the EEG (mainly the low-frequency band) and the hemodynamic modulation may suggest the existence of a coherent prefrontal network for empathy. However, future research should explore the prefrontal localization of the EEG in more depth, also investigating potential cortical generator (e.g., with a LORETA approach) to define the reciprocal contribution by oscillations and hemodynamic measures.

Secondly, regression analyses revealed that brain oscillations and hemodynamic variations might have affected autonomic responses by the subjects. That is, the PFC activity as marked by $\mathrm{O} 2 \mathrm{Hb}$ increases and synchronous cortical activity (mainly for low-frequency bands) were significant factors, able to explain autonomic response modulation since subjects modified their autonomic parameters as a function of EEG/O2Hb changes in an empathic behavioral task. Specifically, increased SCR/HR was predicted by frequency band and hemodynamic activity in response to negative and positive interactions.

To summarize, the direct relation between EEG and $\mathrm{O} 2 \mathrm{Hb}$, shown by correlational values, and the regression analysis, confirmed the interconnections between the three levels of processing (hemodynamic, electrophysiological, and autonomic). Indeed, the two analyses allowed respectively evidencing the direct relationship between the two independent measures (correlation analysis) and their consistent influence on autonomic responses (regression analysis).

In the end, some limitations of this study and future suggestions for improved research should be considered. Firstly, future research should take into account the different roles that emotional and cognitive empathy might have in interpersonal interactions. Secondly, the deeper relations connecting central (both hemodynamic and EEG) and peripheral measures should be explored, considering the temporal course of their modulations in response to empathic situations. Thirdly, the inter-subjective differences related to some personality components (such as empathy as a trait) should be explored as a stable construct able to explain neurophysiological differences. Indeed, possible structural components could have modulated the central and peripheral responses based on subjective empathic and emotional responsiveness to positive and negative situations even in the present study.

\section{REFERENCES}

Avenanti, A., Sirigu, A., \& Aglioti, S. M. (2010). Racial bias reduces empathic sensorimotor resonance with other-race pain. Current Biology, 20, 1018-1022. doi: 10.1016/j.cub.2010.03.071 WWW

Baeken, C., Van Schuerbeek, P., De Raedt, R., De Mey, J., Vanderhasselt, M. A., Bossuyt, A., \& Luypaert, R. (2010). The effect of one left-sided dorsolateral prefrontal cortical HF-rTMS session on emotional brain processes in women. Psychiatria Danubina, 22, S163. doi: 10.1016/j.clinph.2011.04.009 |WWw

Balconi, M., \& Bortolotti, A. (2012a). Detection of the facial expression of emotion and self-report measures in empathic situations are influenced by sensorimotor circuit inhibition by low-frequency rTMS. Brain Stimulation, 5, 330-336. doi: 10.1016/j.brs.2011.05.004 |WWW 
Balconi, M., \& Bortolotti, A. (2012b). Resonance mechanism in empathic behavior. BEES, BIS/BAS and psychophysiological contribution. Physiology and Behavior, 105, 298-304. doi: 10.1016/j.physbeh.2011.08.002 WWW

Balconi, M., \& Bortolotti, A. (2014). Self-report, personality and autonomic system modulation in response to empathic conflictual versus non conflictual situation. Cognition \& Emotion, 28, 153-62. doi: 10.1080/02699931.2013.805685 WwW

Balconi, M., Bortolotti, A., \& Gonzaga, L. (2011). Emotional face recognition, EMG response, and medial prefrontal activity in empathic behaviour. Neuroscience Research, 71, 251-259. doi: 10.1016/j.neures.2011.07.1833 |WWW

Balconi, M., Brambilla, E., \& Falbo, L. (2009a). Appetitive vs. defensive responses to emotional cues. Autonomic measures and brain oscillation modulation. Brain Research, 1296, 72-84. doi: 10.1016/j.brainres.2009.08.056 $\underline{\underline{W W} \mid}$

Balconi, M., Brambilla, E., \& Falbo, L. (2009b). BIS/BAS, cortical oscillations and coherence in response to emotional cues. Brain Research Bulletin, 80, 151-157. doi: 10.1016/j. brainresbull.2009.07.001

Balconi, M., \& Canavesio, Y. (2013). Prosocial attitudes and empathic behavior in emotional positive versus negative situations: brain response (ERPs) and source localization (LORETA) analysis. Cognitive Processing, 14, 63-72. doi: 10.1007/s10339-

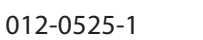

Balconi, M., Falbo, L., \& Conte, V. A. (2012). BIS and BAS correlates with psychophysiological and cortical response systems during aversive and appetitive emotional stimuli processing. Motivation and Emotion, 36, 218-231. doi: 10.1007/s11031-011 $-9244-7$

Balconi, M., Grippa, E., \& Vanutelli, M. E. (2015a). Resting lateralized activity predicts the cortical response and appraisal of emotions: An fNIRS study. Social Cognitive and Affective Neuroscience, 10, 1607-1614. doi: 10.1093/scan/nsv041 $\overline{\text { WWW }}$

Balconi, M., Grippa, E., \& Vanutelli, M. E. (2015b). What hemodynamic (fNIRS), electrophysiological (EEG) and autonomic integrated measures can tell us about emotional processing. Brain and Cognition, 95, 67-76. doi: 10.1016/j.bandc.2015.02.001 WWW

Balconi, M., \& Lucchiari, C. (2006). EEG correlates (event-related desynchronization) of emotional face elaboration: A temporal analysis. Neuroscience Letters, 392, 118-123. doi: 10.1016/j.

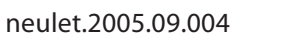

Balconi, M., \& Lucchiari, C. (2008). Consciousness and arousal effects on emotional face processing as revealed by brain oscillations. A gamma band analysis. International Journal of Psychophysiology, 67, 41-46. doi: 10.1016/j. ijpsycho.2007.10.002 www

Balconi, M., \& Mazza, G. (2010). Lateralisation effect in comprehension of emotional facial expression: A comparison between EEG alpha band power and behavioural inhibition
(BIS) and activation (BAS) systems. Laterality, 15, 361-384. doi: 10.1080/13576500902886056 WWW

Balconi, M., \& Pozzoli, U. (2005). Morphed facial expressions elicited a N400 ERP effect: A domain-specific semantic module? Scandinavian Journal of Psychology, 46, 467-474. doi: 10.1111/ j.1467-9450.2005.00478.x

Balconi, M., \& Pozzoli, U. (2008). Event-related oscillations (ERO) and event-related potentials (ERP) in emotional face recognition. The International Journal of Neuroscience, 118, 1412-1424. doi: 10.1080/00207450601047119

Balconi, M., \& Pozzoli, U. (2009). Arousal effect on emotional face comprehension. Frequency band changes in different time intervals. Physiology and Behavior, 97, 455-462. doi: 10.1016/j. physbeh.2009.03.023 WwW

Banks, S. J., Eddy, K. T., Angstadt, M., Nathan, P. J., \& Luan Phan, K. (2007). Amygdala-frontal connectivity during emotion regulation. Social Cognitive and Affective Neuroscience, 2, 303-312. doi: 10.1093/scan/nsm029 WWW

Başar, E. (1999). Brain function and oscillations: Integrative brain function neurophysiology and cognitive processes. Berlin, Germany: Springer. doi: 10.1007/978-3-642-59893-7

Beck, A. T., Steer, R. A., \& Brown, G. K. (1996). Manual for the Beck Depression Inventory - II. San Antonio, TX: Psychological Corporation.

Bekkedal, M. Y. V., Rossi, J., \& Panksepp, J. (2011). Human brain EEG indices of emotions: Delineating responses to affective vocalizations by measuring frontal theta event-related synchronization. Neuroscience and Biobehavioral Reviews, 35, 1959-1970. doi: 10.1016/j.neubiorev.2011.05.001 |WW|

Biallas, M., Trajkovic, I., Haensse, D., Marcar, V., \& Wolf, M. (2012). Reproducibility and sensitivity of detecting brain activity by simultaneous electroencephalography and near-infrared spectroscopy. Experimental Brain Research, 222, 255-264. doi: 10.1007/s00221-012-3213-6 Ww

Biopac Acqknowledge (Version 3.7.1) [Computer software]. Aero Camino Goleta, CA: Biopac Systems Inc.

Biopac MP 150 [Apparatus]. Aero Camino Goleta, CA: Biopac Systems Inc.

Bradley, M. M., \& Lang, P. J. (1994). Measuring emotion: The SelfAssessment Manikin and the Semantic Differential. Journal of Behavior Therapy and Experimental Psychiatry, 25, 49-59. doi: 10.1016/0005-7916(94)90063-9

Bradley, M. M., \& Lang, P. J. (2000). Measuring emotion: Behavior, feeling and physiology. In R. Lane \& L. Nadel (Eds.), Cognitive neuroscience of emotion (pp. 242-276). New York, NY: Oxford University Press.

Bradley, M. M., \& Lang, P. J. (2007). Motivation and emotion. In J. T. Cacioppo, L. G. Tassinary, \& G. G. Berntson (Eds.), Handbook of psychophysiology (pp. 581-607). Cambridge, MA: Cambridge University Press.

BrainVision Analyzer 2 [Computer software]. Munich, Germany: Brainproducts. 
Brink, T. T., Urton, K., Held, D., Kirilina, E., Hofmann, M. J., KlannDelius, G., ... Kuchinke, L. (2011). The role of orbitofrontal cortex in processing empathy stories in 4to 8-year-old children. Frontiers in Psychology, 2:80 doi: 10.3389/fpsyg.2011.00080 WWW

Brown, L. M., Bradley, M. M., \& Lang, P. J. (2006). Affective reactions to pictures of ingroup and outgroup members. Biological Psychology, 71, 303-311. doi: 10.1016/j.biopsycho.2005.06.003 WWW

Brüne, M., Scheele, D., Heinisch, C., Tas, C., Wischniewski, J., \& Güntürkün, O. (2012). Empathy moderates the effect of repetitive transcranial magnetic stimulation of the right dorsolateral prefrontal cortex on costly punishment. PLOS ONE, 7, 1-8. doi: 10.1371/journal.pone.0044747 WWW

Cacioppo, J. T., \& Berntson, G. G. (1994). Relationship between attitudes and evaluative space: A critical review, with emphasis on the separability of positive and negative substrates. Psychological Bulletin, 115, 401-423. doi: 10.1037/0033-2909 .115 .3 .401

Chauhan, B., Mathias, C. J., \& Critchley, H. D. (2008). Autonomic contributions to empathy: Evidence from patients with primary autonomic failure. Autonomic Neuroscience, 140, 96-100. doi: 10.1016/ j.autneu.2008.03.005 $\underline{\underline{W W}}$

Damasio, A. R., Everitt, B. J., \& Bishop, D. (1996). The somatic marker hypothesis and the possible functions of the prefrontal cortex. Philosophical Transactions of the Royal Society of London B: Biological Sciences, 351, 1413-1420. doi: 10.1098/ rstb.1996.0125 $\overline{\mathrm{WWW}}$

Davidson, R. J. (1995). Cerebral asymmetry, emotion and affective style. In R. J. Davidson \& K. Hughdahl (Eds.), Brain asymmetry (pp. 361-387). Cambridge, MA: MIT Press.

Davidson, R. J. (1998). Anterior electrophysiological asymmetries, emotion, and depression: Conceptual and methodological conundrums. Psychophysiology, 35, 607-614. doi: 10.1017/ S0048577298000134 WWW

Davidson, R. J. (2002). Anxiety and affective style: Role of prefrontal cortex and amygdala. Biological Psychiatry, 51, 68-80. doi: 10.1016/S0006-3223(01)01328-2 WWW

Davidson, R. J., Ekman, P., Saron, C. D., Senulis, J. A., \& Friesen, W. V. (1990). Approach-withdrawal and cerebral asymmetry: Emotional expression and brain physiology. I. Journal of Personality and Social Psychology, 58, 330-341.doi: 10.1037/0022-3514.58.2.330 $\underline{\underline{W W}}$

Decety, J., \& Jackson, P. L. (2006). A social neuroscience perspective on empathy. Current Directions in Psychological Science, 15, 54-58. doi: 10.1002/wps.20146

Decety, J., \& Svetlova, M. (2012). Putting together phylogenetic and ontogenetic perspectives on empathy. Developmental Cognitive Neuroscience, 2, 1-24. doi: 10.1016/j.dcn.2011.05.003 WWW

De Raedt, R., Leyman, L., Baeken, C., Van Schuerbeek, P., Luypaert, R., Vanderhasselt, M. A., \&Dannlowski, U. (2010). Neurocognitive effects of HF-rTMS over the dorsolateral prefrontal cortex on the attentional processing of emotional information in healthy women: An event-related fMRI study. Biological Psychology, 85, 487-495. doi: 10.1016/j.biopsycho.2010.09.015 |wWW

Dickinson, A., \& Dearing, M. F. (1978). Appetitive-aversive interactions and inhibitory processes. In A. Dickinson \& R. A. Boakes (Eds.), Mechanisms of learning and motivation: A memorial volume to Jerzy Konorski. Hillsdale, NJ: Lawrence Erlbaum.

Dimberg, U., \& Petterson, M. (2000). Facial reactions to happy and angry facial expressions: Evidence for right hemisphere dominance. Psychophysiology, 37, 693-696. doi: 10.1111/14698986.3750693 WWW

Doi, H., Nishitani, S., \& Shinohara, K. (2013). NIRS as a tool for assaying emotional function in the prefrontal cortex. Frontiers in Human Neuroscience, 7:770. doi: 10.3389/fnhum.2013.00770 WWW

Eippert, F., Veit, R., Weiskopf, N., Erb, M., Birbaumer, N., \& Anders, S. (2007). Regulation of emotional responses elicited by threat-related stimuli. Human Brain Mapping, 28, 409-423. doi: 10.1002/hbm.20291 WWW

Eisenberg, L., Fabes, R. A., Miller, P. A., Fultz, J., Shell, R., Mathy, R. M., \& Reno, R. R. (1989). Relation of sympathy and personal distress to prosocial behavior: A multimethod study. Journal of Personality and Social Psychology, 57, 55-66. doi: 10.1037/00223514.57.1.55

Elwell, C. E., Owen-Reece, H., Cope, M., Wyatt, J. S., Edwards, A. D., Delpy, D. T., \& Reynolds, E. O. (1993). Measurement of adult cerebral haemodynamics using near infrared spectroscopy. Acta Neurochirurgica. Supplementum, 59, 74-80. |WWW

Fanselow, M. S. (1994). Neural organization of the defensive behavior system responsible for fear. Psychonomic Bulletin and Review, 1, 429-438. doi: 10.3758/BF03210947 Www

Fernández, T., Harmony, T., Silva, J., Galín, L., Díaz-Comas, L., Bosch, J., . . Marosi, E. (1998). Relationship of specific EEG frequencies at specific brain areas with performance. Neuroreport, 9, 3680-3687. doi: 10.1097/00001756-199811160-0002 WWW

Furmark, T., Fischer, H., Wik, G., Larsson, M., \& Fredrikson, M. (1997). The amygdala and individual differences in human fear conditioning. Neuroreport, 8, 3957-3960. doi: 10.1097/00001756199712220-00021 WWW

Gutsell, J. N., \& Inzlicht, M. (2012). Intergroup differences in the sharing of emotive states: neural evidence of an empathy gap. Social Cognitive and Affective Neuroscience, 7, 596-603. doi: 10.1093/scan/nsr035 WWW

Herrmann, M. J., Aranda, D., Ellgring, H., Mueller, T. J., Strik, W. K., Heidrich, A., \& Fallgatter, A. J. (2002). Face-specific eventrelated potential in humans is independent from facial expression. International Journal of Psychophysiology, 45, 241-244. doi: 10.1016/S0167-8760(02)00033-8 WWW

Herrmann, M. J., Huter, T., Plichta, M. M., Ehlis, A.-C., Alpers, G. W., Mühlberger, A., \& Fallgatter, A. J. (2008). Enhancement of activity of the primary visual cortex during processing of emotional 
stimuli as measured with event-related functional near-infrared spectroscopy and event-related potentials. Human Brain Mapping, 29, 28-35. doi: 10.1002/hbm.20368 WWW

Hooker, C. I., Verosky, S. C., Germine, L. T., Knight, R. T., \& D’Esposito, M. (2008). Mentalizing about emotion and its relationship to empathy. Social Cognitive and Affective Neuroscience, 3, 204217. doi: 10.1093/scan/nsn019 WWW

Hoshi, Y. (2009). Near-infrared spectroscopy for studying higher cognition. In E. Kraft, B. Gulyás, \& E. Pöppel (Eds.), Neural correlates of thinking. On thinking. (pp. 83-93). Berlin, Germany: Springer-Verlag. doi: 10.1007/978-3-540-68044-4_6

Howard, R., \& McCullagh, P. (2007). Neuroaffective processing in criminal psychopaths: Brain event-related potentials reveal task-specific anomalies. Journal of Personality Disorders, 21,

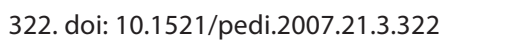

Ickes, W. J. (1997). Empathic accuracy. London, England: Guilford Press.

Kalisch, R., Wiech, K., Critchley, H. D., Seymour, B., O'Doherty, J. P., Oakley, D. A., . . Dolan, R. J. (2005). Anxiety reduction through detachment: Subjective, physiological, and neural effects. Journal of Cognitive Neuroscience, 17, 874-883. doi: 10.1162/0898929054021184 WWW

Karakaş, S., Erzengin, Ö. U., \& Başar, E. (2000). The genesis of human event-related responses explained through the theory of oscillatory neural assemblies. Neuroscience Letters, 285, 45-48. doi: 10.1016/S0304-3940(00)01022-3 |WW

Keil, A., Müller, M. M., Gruber, T., Wienbruch, C., Stolarova, M., \& Elbert, T. (2001). Effects of emotional arousal in the cerebral hemispheres: A study of oscillatory brain activity and eventrelated potentials. Clinical Neurophysiology, 112, 2057-2068. doi: 10.1016/S1388-2457(01)00654-X WWW

Kiehl, K. A., Hare, R. D., McDonald, J. J., \& Brink, J. (1999). Semantic and affective processing in psychopaths: An event-related potential (ERP) study. Psychophysiology, 36, 765-774. doi: 10.1111/1469-8986.3660765 $\overline{\text { WWW }}$

Klimesch, W., Doppelmayr, M., Russegger, H., Pachinger, T., \& Schwaiger, J. (1998). Induced alpha band power changes in the human EEG and attention. Neuroscience Letters, 244, 73-76. doi: 10.1016/S0304-3940(98)00122-0 |

Knyazev, G. G. (2007). Motivation, emotion, and their inhibitory control mirrored in brain oscillations. Neuroscience and Biobehavioral Reviews, 31, 377-395. doi 10.1016/j. neubiorev.2006.10.004 WWW

Krause, L., Enticott, P. G., Zangen, A., \& Fitzgerald, P. B. (2012). The role of medial prefrontal cortex in theory of mind: A deep rTMS study. Behavioural Brain Research, 228, 87-90. doi: 10.1016/j. bbr.2011.11.037 WWW

Lang, P. J., Bradley, M. M., \& Cuthbert, B. N. (1990). Emotion, attention, and the startle reflex. Psychological Review, 97, 377-395. doi: 10.1037/0033-295X.97.3.377 WWW

Lang, P. J., Bradley, M. M., \& Cuthbert, B. N. (1997). Attention and orienting: Sensory and motivational processes. In P. J. Lang,
R. F. Simons, \& M. Balaban (Eds.), Attention and orienting: Sensory and motivational processes (pp. 97-135). Mahwah, NJ: Lawrence Erlbaum Associates.

Lang, P. J., Bradley, M. M., \& Cuthbert, B. N. (1998). Emotion, motivation, and anxiety: Brain mechanisms and psychophysiology. Biological Psychiatry, 44, 1248-1263. doi: 10.1016/S00063223(98)00275-3 Www

Lang, P. J., Davis, M., \& Öhman, A. (2000). Fear and anxiety: Animal models and human cognitive psychophysiology. Journal of Affective Disorders, 61, 137-159. doi: 10.1016/S01650327(00)00343-8 WWW

Lang, P. J., Greenwald, M. K., Bradley, M. M., \& Hamm, A. O. (1993). Looking at pictures: Affective, facial, visceral, and behavioral reactions. Psychophysiology, 30, 261-doi: 10.1111/j.14698986.1993.tb03352.x WWW

Lévesque, J., Eugène, F., Joanette, Y., Paquette, V., Mensour, B., Beaudoin, G., . . Beauregard, M. (2003). Neural circuitry underlying voluntary suppression of sadness. Biological Psychiatry, 53, 502-510. doi: 10.1016/S0006-3223(02)01817-6 WwW

Matsuda, G., \& Hiraki, K. (2006). Sustained decrease in oxygenated hemoglobin during video games in the dorsal prefrontal cortex: A NIRS study of children. Neurolmage, 29, 706-711. doi: 10.1016/j.neuroimage.2005.08.019 $\overline{\mathrm{WWW}}$

Matsuo, K., Kato, T., Taneichi, K., Matsumoto, A., Ohtani, T., Hamamoto, T., ... Kato, N. (2003). Activation of the prefrontal cortex to trauma-related stimuli measured by near-infrared spectroscopy in posttraumatic stress disorder due to terrorism. Psychophysiology, 40, 492-500. doi: 10.1111/1469-8986.00051 WWW

Moghimi, S., Kushki, A., Guerguerian, A. M., \& Chau, T. (2012). Characterizing emotional response to music in the prefrontal cortex using near infrared spectroscopy. Neuroscience Letters, 525, 7-11. doi: 10.1016/j.neulet.2012.07.009 WWW

Moore, A., Gorodnitsky, I., \& Pineda, J. (2012). EEG mu component responses to viewing emotional faces. Behavioural Brain Research, 226, 309-316. doi: 10.1016/j.bbr.2011.07.048 WWW

Morelli, S. A., \& Lieberman, M. D. (2013). The role of automaticity and attention in neural processes underlying empathy for happiness, sadness, and anxiety. Frontiers in Human Neuroscience, 7:160. doi: 10.3389/fnhum.2013.00160

Mu, Y., Fan, Y., Mao, L., \& Han, S. (2008). Event-related theta and alpha oscillations mediate empathy for pain. Brain Research, 1234, 128-136. doi: 10.1016/j.brainres.2008.07.113 |www

NIRScout System [Computer software]. Glen Head, NY: NIRx Medical Technologies LLC.

Nirslab (Version 2014.05) [Computer software]. Glen Head, NY: NIRx Medical Technologies LLC.

NIRStar Acquisition Software [Computer software]. Glen Head, NY: NIRx Medical Technologies LLC.

Nomura, Y., Ogawa, T., \& Nomura, M. (2010). Perspective taking associated with social relationships: A NIRS study. Neuroreport, 21, 1100-1105. doi: 10.1097/WNR.0b013e32834065f5 $\underline{\underline{W W}}$ 
Ochsner, K. N., Bunge, S. A., Gross, J. J., \& Gabrieli, J. D. E. (2002). Rethinking feelings: An FMRI study of the cognitive regulation of emotion. Journal of Cognitive Neuroscience, 14, 1215-1229.

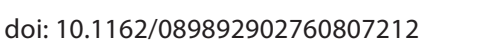

Ochsner, K. N., \& Gross, J. J. (2005). The cognitive control of emotion. Trends in Cognitive Sciences, 9, 242-249. doi: 10.1016/j. tics.2005.03.01 WWW

Ochsner, K. N., Ray, R. D., Cooper, J. C., Robertson, E. R., Chopra, S., Gabrieli, J. D. E., \& Gross, J. J. (2004). For better or for worse: Neural systems supporting the cognitive down- and upregulation of negative emotion. Neurolmage, 23, 483-499. doi:

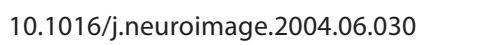

Ogawa, T., \& Nomura, M. (2012). Using NIRS to investigate social relationship in empathic process. In T. Theophanides (Ed.), Infrared Spectroscopy - Life and Biomedical Sciences (pp. 67-78). Rijeka, Croatia: InTech. doi: 10.5772/37057

Ohtani, T., Matsuo, K., Kasai, K., Kato, T., \& Kato, N. (2005). Hemodynamic response to emotional memory recall with eye movement. Neuroscience Letters, 380, 75-79. doi: 10.1016/j. neulet.2005.01.020 $\underline{\underline{W W W}}$

Oldfield, R. C. (1971). The assessment and analysis of handedness: The Edinburgh inventory. Neuropsychologia, 9, 97-113. doi: 10.1016/0028-3932(71)90067-4 WW

Panksepp, J. (1998). Affective neuroscience: The foundations of human and animal emotions. New York, NY: Oxford University Press.

Pera-Guardiola, V., Contreras-Rodríguez, O., Batalla, I., Kosson, D., Menchón, J. M., Pifarré, J., . . Soriano-Mas, C. (2016). Brain structural correlates of emotion recognition in psychopaths. PloS One, 11(5), e0149807. doi: 10.1371/journal.pone.0149807 WWW

Pfurtscheller, G. (1992). Event-related synchronization (ERS): An electrophysiological correlate of cortical areas at rest. Electroencephalography and Clinical Neurophysiology, 83, 62-69. doi: 10.1016/0013-4694(92)90133-3 |

Phan, K. L., Fitzgerald, D. A., Nathan, P. J., Moore, G. J., Uhde, T. W., \& Tancer, M. E. (2005). Neural substrates for voluntary suppression of negative affect: A functional magnetic resonance imaging study. Biological Psychiatry, 57, 210-219. doi: 10.1016/j. biopsych.2004.10.030 WWW

Preston, S. D., \& de Waal, F. B. M. (2002). Empathy: Its ultimate and proximate bases. The Behavioral and Brain Sciences, 25, 1-20. doi: 10.1017/S0140525X02000018 WwW

Prguda, E., \& Neumann, D. L. (2014). Inter-human and animaldirected empathy: A test for evolutionary biases in empathetic responding. Behavioural Processes, 108, 80-86. doi: 10.1016/j. beproc.2014.09.012

Rameson, L.T., \& Lieberman, M. D. (2009). Empathy: A social cognitive neuroscience approach. Social and Personality Psychology Compass, 3, 94-110. doi: 10.1111/j.1751-9004.2008.00154.x

Rameson, L. T., Morelli, S. A., \& Lieberman, M. D. (2012). The neural correlates of empathy: Experience, automaticity, and prosocial behavior. Journal of Cognitive Neuroscience, 24, 235-245. doi: 10.1162/jocn_a_00130 WWW

Rêgo, G. G., Lapenta, O. M., Marques, L. M., Costa, T. L., Leite, J., Carvalho, S., . . Boggio, P. S. (2015). Hemispheric dorsolateral prefrontal cortex lateralization in the regulation of empathy for pain. Neuroscience Letters, 594, 12-16. doi: 10.1016/j.

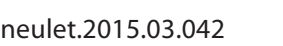

Roos, A., Robertson, F., Lochner, C., Vythilingum, B., \& Stein, D. J. (2011). Altered prefrontal cortical function during processing of fear-relevant stimuli in pregnancy. Behavioural Brain

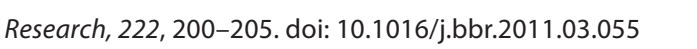

Ruby, P., \& Decety, J. (2004). How would you feel versus how do you think she would feel? A neuroimaging study of perspectivetaking with social emotions. Journal of Cognitive Neuroscience, 16, 988-999. doi: 10.1162/0898929041502661 WWW

Russell, J. (1980). A circumplex model of affect. Journal of Personality and Social Psychology, 39, 1161-1178.

Russell, J. A. (2003). Core affect and the psychological construction of emotion. Psychological Review, 110, 145-172. doi: 10.1037//0033-295X.110.1.145 WWW

Schneider, S., Christensen, A., Häußinger, F. B., Fallgatter, A. J., Giese, M. A., \& Ehlis, A. C. (2014). Show me how you walk and I tell you how you fee - A functional near-infrared spectroscopy study on emotion perception based on human gait. Neurolmage, 85 , 380-390. doi: 10.1016/j.neuroimage.2013.07.078 |wWW

Schroeter, M. L., Zysset, S., Kruggel, F., \& Von Cramon, D. Y. (2003). Age dependency of the hemodynamic response as measured by functional near-infrared spectroscopy. Neurolmage, 19, 555-564. doi: 10.1016/S1053-8119(03)00155-1 | |WW|

Seitz, R. J., Nickel, J., \& Azari, N. P. (2006). Functional modularity of the medial prefrontal cortex: Involvement in human empathy. Neuropsychology, 20, 743-751. doi: 10.1037/0894-4105 20.6.743 wWw

Shamay-Tsoory, S. G., \& Aharon-Peretz, J. (2007). Dissociable prefrontal networks for cognitive and affective theory of mind: A lesion study. Neuropsychologia, 45, 3054-3067. doi: 10.1016/j. neuropsychologia.2007.05.021 $\underline{\underline{\mathrm{WW}}}$

Shimada, S., \& Hiraki, K. (2006). Infant's brain responses to live and televised action. Neurolmage, 32, 930-939. doi: 10.1016/j. neuroimage.2006.03.044

Siegle, G. J., Thompson, W., Carter, C. S., Steinhauer, S. R., \& Thase, M. E. (2007). Increased amygdala and decreased dorsolateral prefrontal BOLD responses in unipolar depression: Related and independent features. Biological Psychiatry, 61, 198-209. doi: 10.1016/j.biopsych.2006.05.048 WwW

Silani, C., \& Singer, T. (2015). Distinct neural networks underlying empathy for pleasant and unpleasant touch. Cortex, 70, 79-89. doi: 10.1016/j.cortex.2015.01.021 wWw

Spielberger, C. D., Gorsuch, R. L., Lushene, R. E., Vagg, P. R., \& Jacobs, G. A. (1970). STAI Manual for the State-Trait Anxiety Inventory. Palo Alto, CA: Consulting Psychologists Press. 
Tanida, M., Katsuyama, M., \& Sakatani, K. (2007). Relation between mental stress-induced prefrontal cortex activity and skin conditions: A near-infrared spectroscopy study. Brain Research, 1184, 210-216. doi: 10.1016/j.brainres.2007.09.058 |WWW

Thirioux, B., Mercier, M. R., Blanke, O., \& Berthoz, A. (2014). The cognitive and neural time course of empathy and sympathy: An electrical neuroimaging study on self-other interaction. Neuroscience, 267, 286-306. doi: 10.1016/j. neuroscience.2014.02.024 WWW

Tullett, A. M., Harmon-Jones, E., \& Inzlicht, M. (2012). Right frontal cortical asymmetry predicts empathic reactions: Support for a link between withdrawal motivation and empathy. Psychophysiology, 49, 1145-1153. doi: 10.1111/j.1469-8986 2012.01395.x WWW

Tupak, S.V., Dresler, T., Guhn, A., Ehlis, A. C., Fallgatter, A. J., Pauli, P., \& Herrmann, M. J. (2014). Implicit emotion regulation in the pres- ence of threat: Neural and autonomic correlates. Neurolmage, 85, 372-379. doi: 10.1016/j.neuroimage.2013.09.066 WWW

Vanutelli, M. E., \& Balconi, M. (2015). Perceiving emotions in human-human and human-animal interactions: Hemodynamic prefrontal activity (fNIRS) and empathic concern. Neuroscience

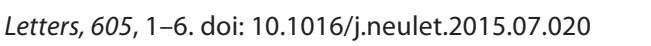

Wang, J., Wang, Y., Hu, Z., \& Li, X. (2014). Transcranial direct current stimulation of the dorsolateral prefrontal cortex increased pain empathy. Neuroscience, 281, 202-207. doi: 10.1016/j. neuroscience.2014.09.044 $\overline{\mathrm{WWW}}$

Wolf, M., Wolf, U., Toronov, V., Michalos, A., Paunescu, L. A., Choi, J. H., \& Gratton, E. (2002). Different time evolution of oxyhemoglobin and deoxyhemoglobin concentration changes in the visual and motor cortices during functional stimulation: A near-infrared spectroscopy study. Neuroimage, 16, 704-712. WWW

RECEIVED 09.09.2016 | ACCEPTED 08.02.2017 